S. G. West $\cdot$ K. D. Hecker $\cdot$ V. A. Mustad $\cdot$ S. Nicholson •

S. L. Schoemer · P. Wagner - A. L. Hinderliter •

J. Ulbrecht · P. Ruey - P. M. Kris-Etherton

\title{
Acute effects of monounsaturated fatty acids with and without omega-3 fatty acids on vascular reactivity in individuals with type 2 diabetes
}

Received: 1 June 2004 / Accepted: 31 July 2004 / Published online: 29 December 2004

(C) Springer-Verlag 2004

\begin{abstract}
Aims/hypothesis: We examined the acute postprandial effects of meals containing unsaturated fatty acids on flow-mediated dilation (FMD) of the brachial artery and triacylglycerols in individuals with type 2 diabetes. We hypothesised that consumption of omega-3 fatty acids would enhance vascular function. Saturated fat reduces FMD for several hours, but there is inconsistent evidence about whether foods containing unsaturated fats impair FMD acutely. Little is known about the acute effects of omega-3 fatty acids on vascular reactivity. Methods: We measured FMD before and $4 \mathrm{~h}$ after 3 test meals $(50 \mathrm{~g}$ fat, $2,615 \mathrm{~kJ})$ in 18 healthy adults with type 2 diabetes. The monounsaturated fatty acids (MUFA) meal contained $50 \mathrm{~g}$ fat from high oleic safflower and canola oils. Two additional meals were prepared by replacing $7 \%$ to $8 \%$ of
\end{abstract}

S. G. West · S. L. Schoemer · P. Wagner · J. Ulbrecht Department of Biobehavioral Health, The Pennsylvania State University,

University Park, PA, USA

K. D. Hecker · P. M. Kris-Etherton

Department of Nutritional Sciences, The Pennsylvania State

University,

University Park, PA, USA

V. A. Mustad · S. Nicholson · P. Ruey

Ross Products Division, Abbott Laboratories,

Columbus, OH, USA

\section{A. L. Hinderliter}

Department of Medicine, Division of Cardiology, University of North Carolina at Chapel Hill,

Chapel Hill, NC, USA

J. Ulbrecht

Department of Medicine, The Pennsylvania State University,

Hershey, PA, USA

S. G. West $(\bowtie)$

Department of Biobehavioral Health,

315 Health and Human Development Building East,

University Park, PA, 16802, USA

e-mail: sgw2@psu.edu

Tel.: +1-814-8630176

Fax: $+1-814-8637256$
MUFA with docosahexaenoic acid and eicosapentaenoic acid from sardine oil or $\alpha$-linolenic acid from canola oil. Results: In the sample as a whole, FMD was increased $17 \%$ at $4 \mathrm{~h}$ vs. the fasting baseline. After the MUFA meal, subjects with the largest increases in triacylglycerols had the largest FMD decreases. The opposite pattern was observed after meals containing docosahexaenoic acid and eicosapentaenoic acid or $\alpha$-linolenic acid. In subjects with high fasting triacylglycerols, meals containing 3 to $5 \mathrm{~g}$ of omega3 fatty acids increased FMD by $50 \%$ to $80 \%$ and MUFA alone had no significant effects on FMD. Conclusions/ interpretation: Endothelium-dependent vasodilation was not impaired $4 \mathrm{~h}$ after meals containing predominantly unsaturated fatty acids. The fatty acid composition of the meal and the metabolic status of the individual determine the vascular effects of a high-fat meal.

Keywords Docosahexaenoic acid · Eicosapentaenoic acid - Endothelium-dependent vasodilation - Flowmediated dilation $\cdot \alpha$-Linolenic acid $\cdot$ Monounsaturated fatty acids · Omega- 3 fatty acids $\cdot$ Type 2 diabetes mellitus

Abbreviations ALA: $\alpha$-linolenic acid $\cdot$ DHA: docosahexaenoic acid - EKG: electrocardiogram - EPA: eicosapentaenoic acid - FMD: flow-mediated dilation . MUFA: monounsaturated fatty acids $\cdot n-3$ : omega-3 fatty acids $\cdot$ SFA: saturated fatty acids

\section{Introduction}

Dysfunction of the vascular endothelium is considered an important initial step in the development of atherosclerosis [1], and endothelial function is impaired in individuals with type 2 diabetes $[2,3]$. Statins significantly improve endothelial function in healthy adults with high cholesterol [4-6], although it is questionable whether this strategy also works in patients with diabetes [7]. In contrast, increased consumption of long-chain omega-3 (n-3) fatty acids is associated with reduced risk of cardiovascular disease in type 2 diabetes [8], and placebo-controlled studies suggest 
that improvements in endothelial function may be a mechanism for this effect [9].

Many previous studies have shown that a single meal containing high levels of saturated fat impairs endothelial function for 2 to $6 \mathrm{~h}$ (for review, see [10, 11]), and there is evidence that other nutrients contained in a meal can modify this response $[12,13]$. Few studies have examined acute vascular effects of polyunsaturated and monounsaturated fatty acids (MUFA) [14-16]. The American Diabetes Association recommends that individuals with diabetes substitute MUFA for saturated fat in their diet [17], and oleic acid is the predominant unsaturated fatty acid in American diets. There is inconsistent evidence about whether diets high in oleic acid have a beneficial $[5,18-20]$, neutral $[9,15,21]$ or negative $[14,16,22]$ impact on markers of endothelial function, and few of the previously published studies were conducted in patients with diabetes.

Because olive oils can vary in their content of saturated and unsaturated fatty acids, we chose to measure the acute effects of blends of primarily unsaturated fatty acids. In this study, we directly compared the vascular and meta- bolic effects of fatty acid blends containing plant-derived and marine-derived n-3 fatty acids in adults with type 2 diabetes, and tested whether their inclusion in a meal altered the postprandial effects of oleic acid.

\section{Subjects, materials and methods}

Subjects We enrolled 18 patients (13 men, 5 women) who had type 2 diabetes mellitus, $\mathrm{HbA}_{1} \mathrm{c}$ levels lower than $9 \%$, and were being treated with diet or oral hypoglycaemic agents only. Table 1 summarises baseline characteristics of the subjects. Most $(n=17)$ had been diagnosed with diabetes within the last 6 years and the majority $(n=16)$ were taking one or more hypoglycaemic drugs; $\mathrm{HbA}_{1} \mathrm{c}$ concentrations ranged from $5.4 \%$ to $8.9 \%$. Other medications used by participants included medications for depression $(n=3)$, anxiety $(n=1)$, pain relief $(n=1)$, inflammation $(n=2)$, and hypothyroidism $(n=2)$.

Potential participants were excluded if they had any of the following: fasting glucose $>16.7 \mathrm{mmol} / \mathrm{l}$; triacylglycerols $>4.5 \mathrm{mmol} / \mathrm{l}$; systolic blood pressure $\geq 160 \mathrm{~mm} \mathrm{Hg}$

Table 1 Baseline characteristics (mean $\pm \mathrm{SE}$ ) of participants

\begin{tabular}{|c|c|c|c|}
\hline & All subjects $(n=18)$ & High triacylglycerols group $(n=8)$ & Low triacylglycerols group $(n=10)$ \\
\hline Age $(\text { years })^{\mathrm{a}}$ & $55.1 \pm 2.1$ & $59.6 \pm 3.2$ & $51.4 \pm 2.3$ \\
\hline Years since diabetes diagnosis & $4.4 \pm 1.6$ & $6 \pm 4$ & $3 \pm 1$ \\
\hline$\%$ Women & $28 \%$ & $38 \%$ & $20 \%$ \\
\hline $\mathrm{HbA}_{1} \mathrm{c}(\%)$ & $7.2 \pm 0.2$ & $7.2 \pm 0.3$ & $7.2 \pm 0.3$ \\
\hline Fasting glucose $(\mathrm{mmol} / \mathrm{l})$ & $7.69 \pm 0.35$ & $8.12 \pm 0.46$ & $7.34 \pm 0.51$ \\
\hline Fasting insulin $(\mu \mathrm{U} / \mathrm{ml})$ & $12.0 \pm 1.5$ & $11.3 \pm 1.7$ & $12.5 \pm 2.3$ \\
\hline HOMA-IR & $4.0 \pm 0.5$ & $4.1 \pm 0.7$ & $4.0 \pm 0.8$ \\
\hline QUICKI & $0.139 \pm 0.004$ & $0.141 \pm 0.004$ & $0.138 \pm 0.0004$ \\
\hline Systolic blood pressure (mm Hg) & $128.2 \pm 1.9$ & $129.4 \pm 2.3$ & $127.3 \pm 3.0$ \\
\hline Diastolic blood pressure (mm Hg) & $78.8 \pm 1.7$ & $79.6 \pm 1.9$ & $78.1 \pm 2.8$ \\
\hline Height (m) & $1.73 \pm 0.02$ & $1.72 \pm 0.03$ & $1.74 \pm 0.03$ \\
\hline Weight (kg) & $87.1 \pm 3.5$ & $84.0 \pm 3.3$ & $89.7 \pm 5.7$ \\
\hline BMI $\left(\mathrm{m} / \mathrm{kg}^{2}\right)$ & $29.2 \pm 0.8$ & $28.6 \pm 0.8$ & $29.6 \pm 1.4$ \\
\hline Triacylglycerols $(\mathrm{mmol} / \mathrm{l})^{\mathrm{a}}$ & $1.95 \pm 0.22$ & $2.70 \pm 0.30$ & $1.34 \pm 0.11$ \\
\hline Total cholesterol $(\mathrm{mmol} / \mathrm{l})^{\mathrm{a}}$ & $5.17 \pm 0.15$ & $5.50 \pm 0.15$ & $4.90 \pm 0.22$ \\
\hline LDL cholesterol (mmol/l) & $3.17 \pm 0.12$ & $3.19 \pm 0.19$ & $3.16 \pm 0.16$ \\
\hline HDL cholesterol (mmol/l) & $1.10 \pm 0.05$ & $1.07 \pm 0.06$ & $1.12 \pm 0.08$ \\
\hline Resting artery diameter $(\mathrm{mm})^{\mathrm{b}}$ & $4.01 \pm 0.13$ & $3.75 \pm 0.20$ & $4.22 \pm 0.17$ \\
\hline Flow-mediated dilation $(\Delta \%)^{\mathrm{c}}$ & $5.18 \pm 0.53$ & $3.76 \pm 0.74$ & $6.31 \pm 0.66$ \\
\hline Resting arterial blood flow ( $\mathrm{ml} / \mathrm{min})$ & $109.4 \pm 7.2$ & $109.3 \pm 11.8$ & $109.4 \pm 10.4$ \\
\hline Hyperaemic flow $(\Delta \%)$ & $613.2 \pm 64.6$ & $502.0 \pm 98.1$ & $702.2 \pm 86.8$ \\
\hline \multicolumn{4}{|c|}{ Number (\%) using oral hypoglycaemic medications } \\
\hline None & $2(11 \%)$ & 0 & $2(20 \%)$ \\
\hline Metformin & $11(62 \%)$ & $7(88 \%)$ & $4(40 \%)$ \\
\hline Secretagogues & $4(22 \%)$ & $3(38 \%)$ & $1(10 \%)$ \\
\hline Thiazolidinediones & $2(11 \%)$ & $1(13 \%)$ & $1(10 \%)$ \\
\hline
\end{tabular}

Artery diameter, flow-mediated dilation, measures of blood flow, glucose, insulin, and HOMA are taken from fasting values, averaged across the three testing days. Triacylglycerols status was determined by the average of four fasting values. All other variables were assessed at the screening visit

${ }^{a}$ Significant group difference, $p<0.05$

${ }^{\mathrm{b}}$ Marginal group difference, $p<0.08$

${ }^{\mathrm{c}}$ Significant group difference when baseline artery diameter is covariate, $p<0.03$ 
systolic; diastolic blood pressure $\geq 95 \mathrm{~mm} \mathrm{Hg}$; body mass index $\left(\mathrm{kg} / \mathrm{m}^{2}\right)>35$; current smoker; history or current diagnosis of cardiovascular disease, diabetic retinopathy, neuropathy, or nephropathy; use of medications or supplements known to affect lipids or blood pressure. In addition to a physician's examination and review of history, a 12lead ECG and fasting blood chemistry panel were conducted. Tests for premenopausal women were scheduled during the early follicular phase (days 1-7) of the menstrual cycle. Written informed consent was obtained, and the protocol was approved by The Pennsylvania State University Institutional Review Board.

Study design A randomised, double-blind, three-phase cross-over design was used. Treatment sessions were separated by at least 7 days. Participants were asked to abstain from alcohol for $48 \mathrm{~h}$, and to discontinue all medications at 1800 hours the night before each test. Flow-mediated dilation (FMD) of the brachial artery was assessed in the right arm twice during each visit, once under fasting conditions and again $4 \mathrm{~h}$ after each meal. Blood samples were collected after a 12-h fast, and $2 \mathrm{~h}$ and $4 \mathrm{~h}$ after each meal. In previous studies, the largest changes in triacylglycerols and FMD have been observed at $4 \mathrm{~h}$ after the meal [23-25].

Test meals We compared the acute effects of three MUFArich test meals, which differed in the amount and type of n-3 fatty acids they contained (Table 2). Test meals were freshly prepared and contained $473 \mathrm{ml}$ skimmed milk, 50 $\mathrm{g}$ fat from one of three blends of unsaturated fatty acids, ice, and flavourings designed to mask the characteristic aroma and flavours of the oils (Ross Products Division, Abbott Laboratories, Columbus, OH, USA). Meals were presented in an unmarked container, and participants consumed the meals within $15 \mathrm{~min}$. The control meal was high in MUFA and was prepared with high oleic safflower oil (90\%) and canola oil (10\%). It contained $0.5 \mathrm{~g}$ of $\mathrm{n}-3$ fatty acids from $\alpha$-linolenic acid (C18:3n-3; ALA). The ALA+MUFA test meal was prepared with canola oil $(70 \%)$, high oleic safflower oil $(20 \%)$ and safflower oil

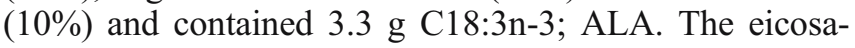

pentaenoic acid (EPA)/docosahexaenoic acid (DHA) +MUFA test meal contained $60 \%$ high oleic safflower oil, 25\% safflower oil and 15\% sardine oil and provided $2.8 \mathrm{~g}$ eicosapentaenoic acid (C20:5n-3; EPA) and $1.2 \mathrm{~g}$ docosahexaeneoic acid (C22:6n-3; DHA), and $0.2 \mathrm{~g}$ of ALA.

Assessment of vascular reactivity The ultrasound protocol closely followed recommendations by Corretti et al. [26], and it has been described in detail previously [27]. Brachial arterial diameter and flow velocity were measured using an Acuson 128XP duplex ultrasound imaging system (Siemens, New York, NY, USA) with a $10-\mathrm{MHz}$ linear array transducer. Longitudinal, two-dimensional images of the brachial artery 5 to $10 \mathrm{~cm}$ above the elbow of the right arm were stored on SVHS tape during quiet rest (1 min), arterial occlusion via inflation of a cuff on the forearm (distal to the target artery) to $200 \mathrm{~mm} \mathrm{Hg}$ (5 $\mathrm{min})$, and reactive hyperaemia ( $2 \mathrm{~min}$ ) by a sonographer with extensive training in vascular ultrasound. All images were of sufficient quality to be included in the analyses.

Frames for analysis were sampled at end diastole and diameters were measured continuously using automated edge-detection software (Brachial Analyzer; Medical Imaging Applications, Iowa City, IA, USA), with manual review of arterial boundaries by a trained technician, and confirmation by a second technician. FMD was measured as the percent change $(\Delta \%)$ in arterial diameter from the average diameter under resting conditions to the peak diameter recorded during the deflation period. Blood flow was measured by spectral Doppler at rest and within 15 seconds of cuff release as flow $(\mathrm{ml} / \mathrm{min})=$ velocity time integral $\times$ cross-sectional area of the vessel $\times$ heart rate, and percent change in flow is reported here.

Biological analyses At screening, blood samples were assayed for lipids and lipoproteins, liver and kidney function, complete blood count, $\mathrm{HbA}_{1} \mathrm{c}$, glucose, and insulin by American Medical Laboratories (Chantilly, VA, USA). Triacylglycerols were analysed using standard enzymatic procedures with commercially available kits (Abbott Laboratories, Diagnostic Division, Irving, TX,

\begin{tabular}{|c|c|c|c|c|c|c|c|}
\hline & & & & & & & \\
\hline $\begin{array}{l}\text { Table } 2 \mathrm{C} \\
\text { meals }\end{array}$ & & MUFA & & $\mathrm{ALA}+\mathrm{MUH}$ & & EPA/DHA + & +MUFA \\
\hline & Energy $(\mathrm{kJ})$ & 2,615 & & 2,615 & & 2,615 & \\
\hline composition of the oil & & Weight $(\mathrm{g})$ & $\%$ Energy & Weight $(\mathrm{g})$ & $\%$ Energy & Weight $(g)$ & $\%$ Energy \\
\hline composition of carbohydrates & Protein (from skimmed milk) & 20 & $13 \%$ & 20 & $13 \%$ & 20 & $13 \%$ \\
\hline and protein content of test meals & Carbohydrate (from skimmed milk) & 24 & $15 \%$ & 24 & $15 \%$ & 24 & $15 \%$ \\
\hline was calculated using food & Total fat & 50 & $72.0 \%$ & 50 & $72.0 \%$ & 50 & $72.0 \%$ \\
\hline $\begin{array}{l}\text { analysis tables } \\
A L A \alpha \text {-linolenic acid, } D H A\end{array}$ & $\mathrm{SFA}^{\mathrm{a}}$ & 4.5 & $6.5 \%$ & 3.5 & $5.0 \%$ & 5 & $7.0 \%$ \\
\hline docosahexaenoic acid, $E P A$ & MUFA $^{\mathrm{a}}$ & 32.6 & $47.0 \%$ & 31.2 & $44.9 \%$ & 30.7 & $44.2 \%$ \\
\hline eicosapentaenoic acid, $L A$ & PUFA $^{\mathrm{a}}$ & 9.8 & $14.1 \%$ & 12.8 & $18.4 \%$ & 11.8 & $17 \%$ \\
\hline linoleic acid, $M U F A$ & $\mathrm{LA}^{\mathrm{a}}$ & 9.2 & $13.3 \%$ & 9.2 & $13.2 \%$ & 6.1 & $8.8 \%$ \\
\hline $\begin{array}{l}\text { monounsaturated fatty acids, } n-3 \\
\text { omega } 3 \text { fatty acids, } P U F A\end{array}$ & $n-3^{a}$ & 0.5 & $0.8 \%$ & 3.3 & $4.8 \%$ & 4.8 & $6.9 \%$ \\
\hline polyunsaturated fatty acids, SFA & $\mathrm{ALA}^{\mathrm{a}}$ & 0.5 & - & 3.3 & - & 0.2 & - \\
\hline saturated fatty acids & $\mathrm{EPA}^{\mathrm{a}}$ & 0 & - & 0 & - & 2.76 & - \\
\hline${ }^{\mathrm{a}}$ Fatty acids make up approxi- & $\mathrm{DHA}^{\mathrm{a}}$ & 0 & - & 0 & - & 1.16 & - \\
\hline
\end{tabular}


USA; Laboratory of Petar Alaupovic, Oklahoma Medical Research Foundation, Oklahoma City, OK, USA). Glucose was analysed via a portable enzymatic device (Precision, Abbott Laboratories, Medisense Products, Bedford, MA, USA). Serum insulin was measured using a solid-phase radioimmunoassay (Coat-A-Count diagnostic products, Los Angeles, CA, USA) based on insulin-specific antibodies and ${ }^{125}$ I-labelled insulin tracers [28]. Insulin resistance and sensitivity scores [29] were calculated from fasting values of insulin and glucose as follows: HOMA$\mathrm{IR}=$ glucose $(\mathrm{mmol} / \mathrm{l}) \times$ insulin $(\mu \mathrm{U} / \mathrm{ml}) / 22.5$ and QUICKI $=$ $1 /(\log$ insulin $\times \log$ glucose), where glucose is measured in milligrams per decilitre and insulin is measured in microunit per millilitre.

Statistical analyses All variables were analysed using a mixed models approach and SAS PROC MIXED (SAS v. 8, Cary, NC, USA). Models included treatment, time and visit number as fixed effects, and subject as a random effect. There were no significant effects of treatment order. When significant effects of time were found, we examined the effect of treatment on change scores (postprandial level-fasted level). Tukey-Kramer adjusted $p$ values were used to examine the source of significant effects, and all analyses of FMD and blood flow were adjusted for basal artery diameter. Text and tables report least squares means \pm SE, and probability values of $\leq 0.05$ were considered statistically significant.

Interrelationships between the variables were estimated by partial Pearson correlation coefficients. Because fasting triacylglycerols concentration is an important predictor of postprandial metabolic and vascular response, we separately examined the effects of treatment in patients with high $(\geq 1.69 \mathrm{mmol} / \mathrm{l}, n=8)$ vs. low $(<1.69 \mathrm{mmol} / \mathrm{l}, n=10)$ fasting triacylglycerols, based on the average of four fasting values and utilising the National Cholesterol Education Program criterion to define high triacylglycerols [30]. $t$ Tests, analysis of covariance, and chi-square tests were used to compare the two groups on characteristics at study entry (see Table 1). Mixed models analyses were repeated as described above, with the triacylglycerols group and its interactions as additional fixed effects. In keeping with Herrington et al. [31], we calculated the coefficient of variation for fasting FMD for each participant as $\mathrm{CV}=\mathrm{SD} \times 100 /$ mean. Our $\mathrm{CV}$ was $29.7 \%$, which is in the low range of published values [31].

\section{Results}

Predictors of fasting flow-mediated dilation As expected, lower fasting FMD was associated with increasing age $(r=$ $-0.72, p=0.001)$ and higher systolic blood pressure $(r=$ $-0.50, p=0.04)$. There was no relationship between fasting FMD and insulin, glucose, or markers of insulin sensitivity/resistance.

Vascular and metabolic effects of fatty acid blends Table 3 shows postprandial changes for each of the outcome variables. Regardless of the fatty acid composition of the test meals, average FMD increased by $17 \%$ at $4 \mathrm{~h}$, relative to the fasting baseline (average $\mathrm{FMD}=5.16 \pm 0.51$ vs. $6.04 \pm 0.51$, at $0 \mathrm{~h}$ vs. $4 \mathrm{~h}$, respectively, $p=0.01$ ). However, there was considerable individual variability in magnitude and direction of the postprandial change in FMD (Fig. 1ac), and in some subjects FMD actually decreased in response to the meal. The treatments did not differ in their effects on resting arterial blood flow or the magnitude of the hyperaemic flow response. Regardless of the type of meal consumed, resting arterial blood flow significantly decreased $4 \mathrm{~h}$ after each of the treatments $(p<0.001$; Table 3), and the hyperaemic flow response was un-

Table 3 Effects of test meals on vascular and metabolic parameters

\begin{tabular}{|c|c|c|c|}
\hline & Fasted & $2 \mathrm{~h}$ & $4 \mathrm{~h}$ \\
\hline \multicolumn{4}{|c|}{ Flow-mediated dilation ${ }^{\mathrm{a}}(\Delta \%)$} \\
\hline MUFA & $5.08 \pm 0.61$ & - & $5.82 \pm 0.61$ \\
\hline EPA/DHA & $4.92 \pm 0.61$ & - & $5.62 \pm 0.61$ \\
\hline ALA & $5.47 \pm 0.61$ & - & $6.67 \pm 0.61$ \\
\hline \multicolumn{4}{|c|}{ Resting artery diameter (mm) } \\
\hline MUFA & $4.03 \pm 0.14$ & - & $4.02 \pm 0.14$ \\
\hline EPA/DHA & $4.02 \pm 0.14$ & - & $4.06 \pm 0.14$ \\
\hline ALA & $3.98 \pm 0.14$ & - & $4.01 \pm 0.14$ \\
\hline \multicolumn{4}{|c|}{ Peak artery diameter (mm) } \\
\hline MUFA & $4.23 \pm 0.14$ & - & $4.24 \pm 0.14$ \\
\hline EPA/DHA & $4.22 \pm 0.14$ & - & $4.27 \pm 0.14$ \\
\hline ALA & $4.20 \pm 0.14$ & - & $4.27 \pm 0.14$ \\
\hline \multicolumn{4}{|c|}{ Resting blood flow $(\mathrm{ml} / \mathrm{min})^{\mathrm{a}}$} \\
\hline MUFA & $110.4 \pm 7.6$ & - & $95.9 \pm 7.6$ \\
\hline $\mathrm{EPA} / \mathrm{DHA}$ & $112.2 \pm 7.6$ & - & $89.2 \pm 7.6$ \\
\hline ALA & $105.8 \pm 7.6$ & - & $98.5 \pm 7.6$ \\
\hline \multicolumn{4}{|c|}{ Hyperaemic flow $(\Delta \%)$} \\
\hline MUFA & $518.1 \pm 77.1$ & - & $664.4 \pm 74.9$ \\
\hline EPA/DHA & $601.7 \pm 74.9$ & - & $595.9 \pm 74.9$ \\
\hline ALA & $646.7 \pm 75.1$ & - & $607.9 \pm 74.9$ \\
\hline \multicolumn{4}{|c|}{ Triacylglycerols $(\mathrm{mmol} / \mathrm{l})^{\mathrm{a}, \mathrm{b}, \mathrm{c}}$} \\
\hline MUFA & $1.65 \pm 0.20$ & $2.38 \pm 0.20$ & $2.71 \pm 0.20$ \\
\hline EPA/DHA & $1.64 \pm 0.20$ & $2.26 \pm 0.20$ & $2.45 \pm 0.20$ \\
\hline ALA & $1.49 \pm 0.20$ & $2.25 \pm 0.20$ & $2.30 \pm 0.20$ \\
\hline \multicolumn{4}{|c|}{ Glucose $(\mathrm{mmol} / \mathrm{l})^{\mathrm{a}, \mathrm{c}}$} \\
\hline MUFA & $7.89+0.39$ & $7.56 \pm 0.39$ & $6.06 \pm 0.39^{\mathrm{d}}$ \\
\hline EPA/DHA & $7.50 \pm 0.39$ & $7.22 \pm 0.39$ & $5.89 \pm 0.39^{\mathrm{d}}$ \\
\hline ALA & $7.67 \pm 0.39$ & $7.61 \pm 0.39$ & $6.11 \pm 0.39^{\mathrm{d}}$ \\
\hline \multicolumn{4}{|c|}{ Insulin $(\mu \mathrm{U} / \mathrm{ml})^{\mathrm{a}}$} \\
\hline MUFA & $11.60 \pm 1.87$ & $23.20 \pm 1.89^{\mathrm{d}}$ & $13.00 \pm 1.89$ \\
\hline $\mathrm{EPA} / \mathrm{DHA}$ & $12.22 \pm 1.87$ & $22.01 \pm 1.89^{\mathrm{d}}$ & $13.19 \pm 1.87$ \\
\hline ALA & $12.15 \pm 1.87$ & $23.88 \pm 1.89^{\mathrm{d}}$ & $13.46 \pm 1.89$ \\
\hline
\end{tabular}

LS $(n=18)$ means \pm SE

$A L A \alpha$-linolenic acid, DHA docosahexaenoic acid, EPA eicosapentaenoic acid, MUFA monounsaturated fatty acids

${ }^{\mathrm{a}}$ Main effect of time, $p \leq 0.01$

${ }^{\mathrm{b}}$ Main effect of treatment, $p<0.05$, for average of three readings being significantly lower during ALA vs. MUFA

${ }^{\mathrm{c}}$ Main effect of visit, $p<0.04$ (data not shown)

${ }^{\mathrm{d}}$ For change vs. fasting values, $p<0.05$ 
Fig. 1 Flow-mediated dilation of the brachial artery $(\mathbf{a}, \mathbf{b}, \mathbf{c})$ in 18 participants before and $4 \mathrm{~h}$ after high-fat meals containing MUFA alone (a), EPA/DHA +MUFA (b), or ALA+MUFA (c). Correlation $(\mathbf{d}, \mathbf{e}, \mathbf{f})$ between postprandial change (increase or decrease) in flow-mediated dilation and postprandial increase (absolute change) in triacylglycerol concentrations for MUFA alone (d), EPA/DHA +MUFA (e), or ALA+MUFA (f). Correlations for the three test meals were as follows: $r=-0.50$, $p<0.05$ for the MUFA meal; $r=0.49, p=0.052$ for the EPA/ DHA meal; and $r=0.49$, $p=0.046$ for the ALA meal. $A L A$ $\alpha$-linolenic acid, $D H A$ docosahexaenoic acid, EPA eicosapentaenoic acid, FMD flowmediated dilation, MUFA monounsaturated fatty acids, $T G$ triacylglycerols

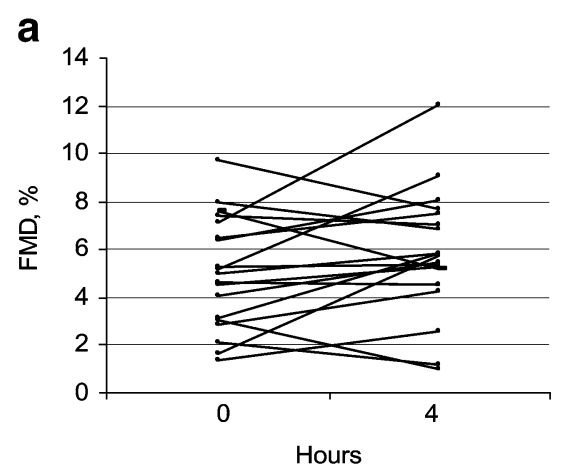

MUFA

d

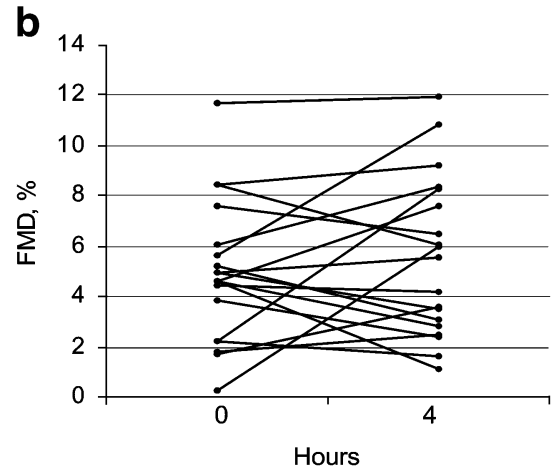

EPA/DHA + MUFA

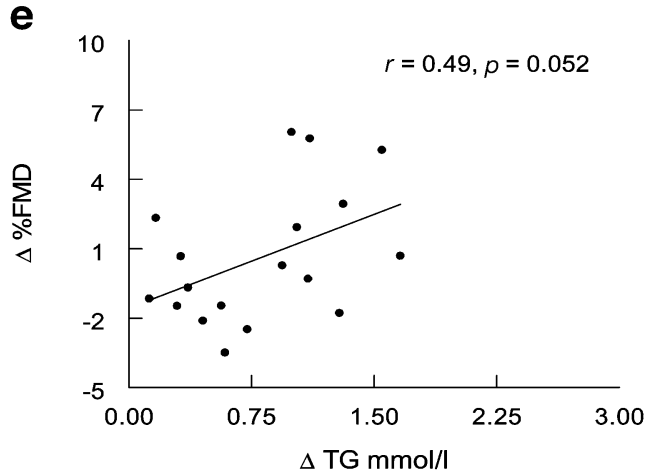

$A L A+M U F A$

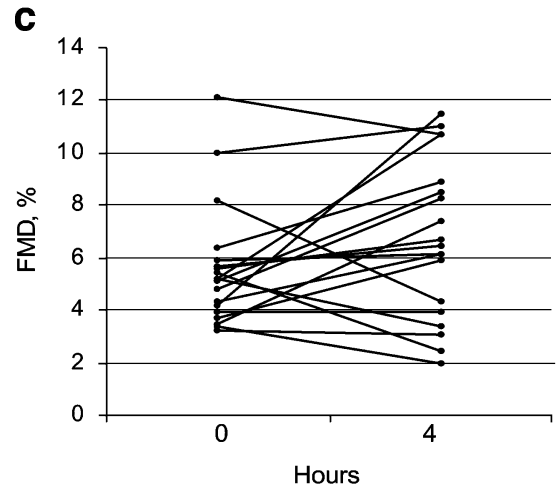

changed. As expected, triacylglycerols significantly increased after each meal, and the largest change was observed at $4 \mathrm{~h}$ after the meal. Insulin concentrations increased $92 \%$ at $2 \mathrm{~h}(p<0.05)$, and returned to baseline at 4 h. Glucose was significantly lower at $4 \mathrm{~h}$ postmeal vs. fasting levels $(p<0.001)$.

Predictors of postprandial change in FMD Figure $1 \mathrm{~d}-\mathrm{f}$ shows the relationship between change in FMD and change in triacylglycerols at $4 \mathrm{~h}$ postprandial, separately for each of the three test meals. During the MUFA meal only, there was a significant inverse correlation between change in triacylglycerols and change in FMD $(r=-0.50$, $p<0.05)$, such that subjects with the largest triacylglycerols increases after the MUFA meal exhibited the largest reductions in endothelium-dependent vasodilation. The opposite pattern was observed when test meals included 3 to $4 \mathrm{~g}$ of $\mathrm{n}-3$ fatty acids such as ALA or EPA/DHA. During these test meals, larger increases in plasma triacylglycerols were associated with larger increases/improvements in FMD. The magnitude of this correlation was similar after consumption of EPA/DHA+MUFA $(r=0.49, p=0.052)$ and ALA+MUFA $(r=0.49, p=0.046)$. Postmeal changes in FMD were not correlated with any of the fasting metabolic or vascular parameters, nor with changes in insulin, glucose, arterial blood flow, blood pressure, or heart rate.

Effects of fasting triglyceride status on cardiac risk markers Because it is well known that individuals with high fasting triacylglycerols also exhibit larger absolute 
Table 4 Effects of test meals on vascular and metabolic parameters in subjects having high or low fasting triacylglycerols

LS means \pm SE

$A L A \alpha$-linolenic acid, $D H A$ docosahexaenoic acid, EPA eicosapentaenoic acid, MUFA monounsaturated fatty acids ${ }^{\mathrm{a}}$ Main effect of time, $p<0.02$

${ }^{\mathrm{b}}$ Time-group-treatment interaction, $p \leq 0.04$

${ }^{c}$ Main effect of group, $p \leq 0.05$

${ }^{\mathrm{d}}$ Main effect of treatment, $p=0.03$, for average of three readings being significantly lower during ALA vs. MUFA

${ }^{\mathrm{e}}$ Main effect of visit, $p=0.0001$ (data not shown)

${ }^{\mathrm{f}}$ Significant change vs. fasting values, $p<0.05$

\begin{tabular}{|c|c|c|c|c|c|c|}
\hline & \multicolumn{3}{|c|}{ High fasting triacylglycerols } & \multicolumn{3}{|c|}{ Low fasting triacylglycerols } \\
\hline & Fasted & $2 \mathrm{~h}$ & $4 \mathrm{~h}$ & Fasted & $2 \mathrm{~h}$ & $4 \mathrm{~h}$ \\
\hline \multicolumn{7}{|c|}{ Flow-mediated dilation $(\Delta \%)^{\mathrm{a}, \mathrm{b}, \mathrm{c}}$} \\
\hline MUFA & $3.76 \pm 0.83$ & - & $3.87 \pm 0.83$ & $6.15 \pm 0.74$ & - & $7.38 \pm 0.74$ \\
\hline EPA/DHA & $2.98 \pm 0.83$ & - & $5.35 \pm 0.83^{\mathrm{f}}$ & $6.48 \pm 0.74$ & - & $5.88 \pm 0.75$ \\
\hline ALA & $3.89 \pm 0.84$ & - & $5.95 \pm 0.83^{\mathrm{f}}$ & $6.69 \pm 0.74$ & - & $7.24 \pm 0.74$ \\
\hline \multicolumn{7}{|c|}{ Resting artery diameter (mm) } \\
\hline MUFA & $3.76 \pm 0.20$ & - & $3.78 \pm 0.20$ & $4.25 \pm 0.18$ & - & $4.20 \pm 0.18$ \\
\hline EPA/DHA & $3.78 \pm 0.20$ & - & $3.80 \pm 0.20$ & $4.21 \pm 0.18$ & - & $4.27 \pm 0.18$ \\
\hline ALA & $3.70 \pm 0.20$ & - & $3.76 \pm 0.20$ & $4.20 \pm 0.18$ & - & $4.21 \pm 0.18$ \\
\hline \multicolumn{7}{|c|}{ Peak artery diameter $(\mathrm{mm})^{\mathrm{c}}$} \\
\hline MUFA & $3.92 \pm 0.19$ & - & $3.94 \pm 0.19$ & $4.48 \pm 0.17$ & - & $4.49 \pm 0.17$ \\
\hline EPA/DHA & $3.91 \pm 0.19$ & - & $4.02 \pm 0.19$ & $4.46 \pm 0.17$ & - & $4.48 \pm 0.17$ \\
\hline ALA & $3.87 \pm 0.19$ & - & $4.00 \pm 0.19$ & $4.45 \pm 0.17$ & - & $4.48 \pm 0.17$ \\
\hline \multicolumn{7}{|c|}{ Resting blood flow $(\mathrm{ml} / \mathrm{min})^{\mathrm{a}}$} \\
\hline MUFA & $104.0 \pm 11.6$ & - & $98.7 \pm 11.5$ & $116.8 \pm 10.4$ & - & $93.1 \pm 10.3$ \\
\hline EPA/DHA & $118.9 \pm 11.5$ & - & $97.6 \pm 11.5$ & $105.5 \pm 10.3$ & - & $80.8 \pm 10.4$ \\
\hline ALA & $103.3 \pm 11.7$ & - & $110.1 \pm 11.6$ & $108.3 \pm 10.3$ & - & $86.9 \pm 10.3$ \\
\hline \multicolumn{7}{|c|}{ Hyperaemic flow $(\Delta \%)^{\mathrm{c}}$} \\
\hline MUFA & $456.9 \pm 114.1$ & - & $422.0 \pm 113.8$ & $579.4 \pm 109.0$ & - & $906.7 \pm 101.6$ \\
\hline EPA/DHA & $417.6 \pm 113.7$ & - & $442.2 \pm 113.4$ & $785.8 \pm 101.7$ & - & $749.6 \pm 102.9$ \\
\hline ALA & $526.8 \pm 115.4$ & - & $509.8 \pm 114.0$ & $766.6 \pm 101.6$ & - & $706.1 \pm 101.7$ \\
\hline \multicolumn{7}{|c|}{ Triacylglycerols $(\mathrm{mmol} / \mathrm{l})^{\mathrm{a}, \mathrm{b}, \mathrm{d}, \mathrm{e}}$} \\
\hline MUFA & $2.18 \pm 0.23$ & $3.15 \pm 0.24^{\mathrm{f}}$ & $3.51 \pm 0.24^{\mathrm{f}}$ & $1.25 \pm 0.21$ & $1.80 \pm 0.21^{\mathrm{f}}$ & $2.11 \pm 0.21^{\mathrm{f}}$ \\
\hline EPA/DHA & $2.40 \pm 0.23$ & $2.91 \pm 0.24^{\mathrm{f}}$ & $3.06 \pm 0.23^{\mathrm{f}}$ & $1.25 \pm 0.21$ & $1.74 \pm 0.21^{\mathrm{f}}$ & $1.95 \pm 0.21^{\mathrm{f}}$ \\
\hline ALA & $2.06 \pm 0.23$ & $2.61 \pm 0.24^{\mathrm{f}}$ & $2.92 \pm 0.23^{\mathrm{f}}$ & $1.15 \pm 0.21$ & $1.95 \pm 0.21^{\mathrm{f}}$ & $1.80 \pm 0.22^{\mathrm{f}}$ \\
\hline
\end{tabular}

changes in triacylglycerols following a high-fat meal, we compared postprandial responses in subjects with high vs. low fasting triacylglycerols. As shown in Table 1, individuals in the high triacylglycerols group were significantly older $(p<0.05)$, had higher total cholesterol $(p=0.05)$, and were taking more medications to control their diabetes than individuals in the low triacylglycerols group. There were no significant group differences in $\mathrm{HbA}_{1} \mathrm{c}$, fasting insulin, glucose, HOMA-IR, or QUICKI under fasting conditions. There was a trend for the high triacylglycerols group to have smaller brachial artery diameter $(p=0.08)$. When basal artery diameter was used as a covariate, fasting FMD was significantly lower in the high triacylglycerols group $(p=0.03)$.

Group differences in postprandial responses to the meals Table 4 shows the pattern of postprandial responses, separately for individuals with high vs. low fasting triacylglycerols. During the MUFA treatment, the postprandial triacylglycerols change (absolute increase) was larger in the high triacylglycerols group than in the low triacylglycerols group $(p=0.01$; Fig. 2a), as expected. However, the two groups did not differ when test meals included ALA or EPA/DHA, and there was a significant group-treatment interaction for triacylglycerols change $(p<0.05)$. A different pattern was seen for postprandial change in FMD (Fig. 2b). Following the MUFA meal, there were no significant changes in FMD in either group of subjects. However, when test meals included plantderived or marine-derived n-3 fatty acids, the high

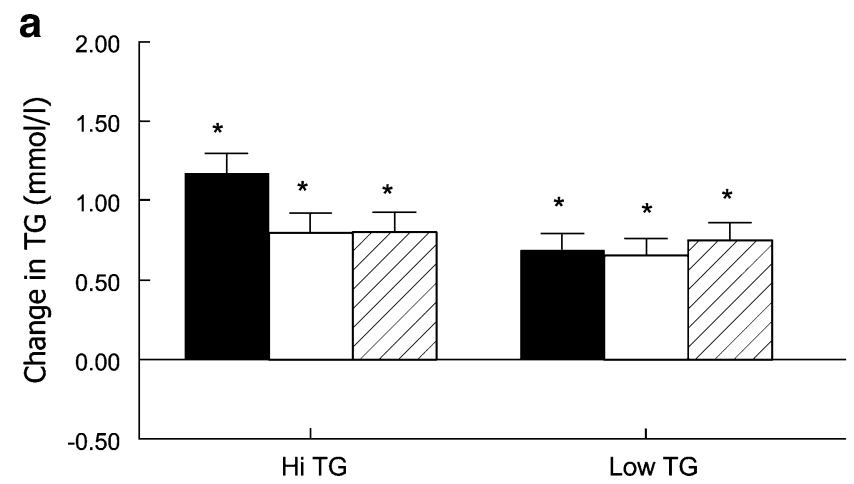

b

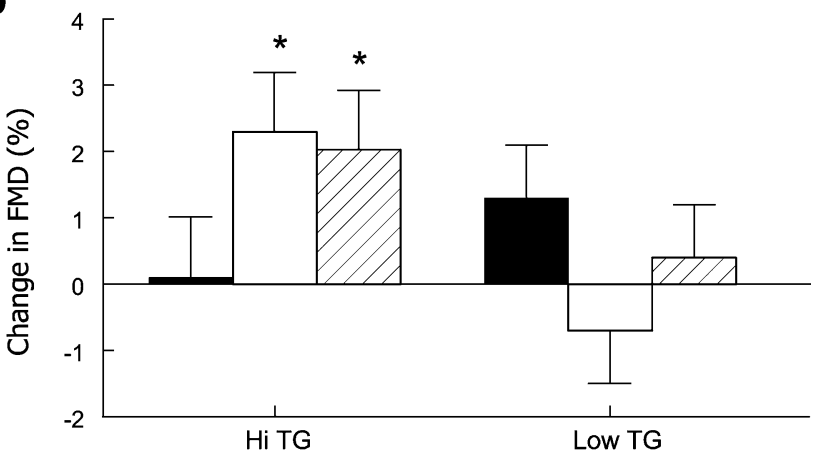

Fig. 2 Mean change in triacylglycerol $(T G)$ concentrations (a) and flow-mediated dilation $(F M D)$ (b) in subjects with high vs. low fasting triacylglycerol levels, at $4 \mathrm{~h}$ after the meal. Dark bars MUFA alone, open bars EPA/DHA+MUFA, striped bars ALA+MUFA. ${ }^{*} p \leq 0.03$ for significant change vs. fasted baseline. Abbreviations, see Fig. 1 
a

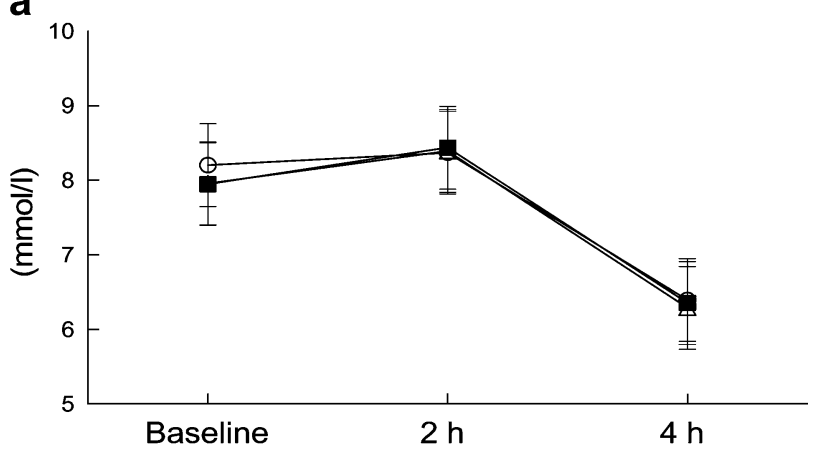

b

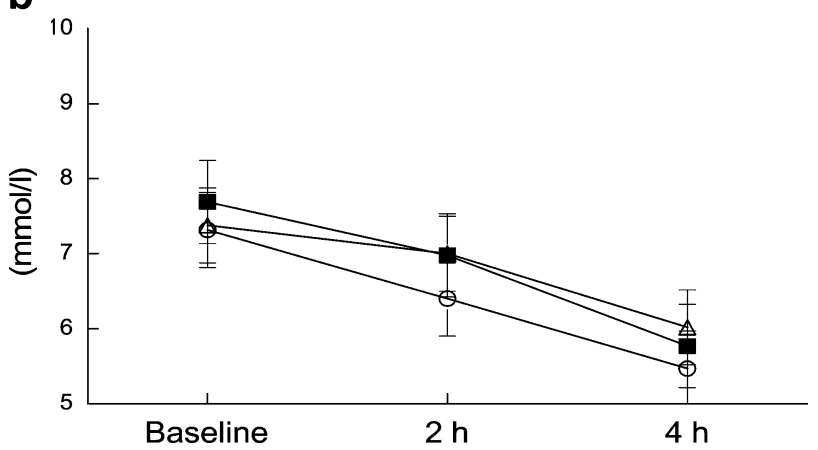

Fig. 3 Effects of test meals on postprandial glucose concentrations in participants with (a) high vs. (b) low fasting triacylglycerol levels. Black squares MUFA alone, open circles EPA/DHA+MUFA, open triangles ALA+MUFA. Abbreviations, see Fig. 1

triacylglycerols group showed significant increases in FMD at $4 \mathrm{~h}(p \leq 0.04)$. This response resulted in a significant treatment-group interaction for FMD change $(p<0.03)$.

Figure $3 \mathrm{a}$ and $\mathrm{b}$ show that meal composition had no effect on glucose levels. However, there was a significant group-time interaction for glucose $(p<0.05)$. The low triacylglycerols group had significant reductions in plasma glucose at $2 \mathrm{~h}(p=0.01)$, while glucose remained elevated in the high triacylglycerols group. At $4 \mathrm{~h}$ postmeal, the two groups had equivalent reductions in glucose. In addition, there were no significant effects of time or fatty acid composition of the meal on the magnitude of the hyperaemic response. There were no significant effects of treatment on blood pressure or heart rate. Regardless of the type of treatment, blood pressure was lower at $2 \mathrm{~h}$ than at 4 h $(p=0.003$, means $85 \pm 1,84 \pm 1,87 \pm 1 \mathrm{~mm} \mathrm{Hg}$, at baseline, $2 \mathrm{~h}$, and $4 \mathrm{~h}$, respectively). Heart rate was significantly elevated at $4 \mathrm{~h}$ vs. the fasting baseline in the high triacylglycerols group only (means $63 \pm 3$ vs. $67 \pm 3 \mathrm{bpm}$, $p=0.0001)$.

\section{Discussion}

In contrast to previous studies showing impaired endothelial function after high-fat meals containing olive oil [14] or saturated fat [23, 32-34], FMD was not impaired $4 \mathrm{~h}$ after a high-fat meal containing predominantly unsaturated fatty acids. In fact, when the sample as a whole was considered, FMD significantly increased at $4 \mathrm{~h}$. However, fasting triacylglycerols status, triacylglycerols response to the meals, and the fatty acid profile of the meals were important determinants of the direction and magnitude of postprandial responses. Subjects with elevated triacylglycerols concentrations showed significant FMD impairment under fasting conditions, slower clearance of glucose following a meal, and larger triacylglycerols increases after a meal containing $50 \mathrm{~g}$ of the MUFA fat blend when compared to the low triacylglycerols group. Importantly, however, when $7 \%$ to $8 \%$ of the MUFA fat blend was replaced with n-3 fatty acids from canola or sardine oil, the high triacylglycerols group exhibited significant increases in FMD and smaller increases in postprandial triacylglycerols concentrations (Fig. 2).

It is tempting to speculate that FMD improvements in the high triacylglycerols group in response to n-3 fatty acids were a direct result of the smaller increases in triacylglycerols that followed meals containing EPA/DHA and ALA. However, our data do not support a straightforward, causal link. During the MUFA meal there was a significant inverse correlation between change in triacylglycerols and change in FMD. In contrast, when test meals included either plant-derived or marine-derived polyunsaturated fatty acids, subjects with the largest increases in triacylglycerols had the largest improvements in FMD.

This apparent contradiction highlights an important issue in the study of triglyceride-rich lipoproteins: the composition of postprandial triacylglycerol particles generally reflects the fatty acid composition of the meal itself $[35,36]$. Therefore, the increase in triacylglycerols after the MUFA meal may indicate higher circulating levels of oleic acid, which appears to be neutral with respect to FMD, while consumption of ALA or EPA/DHA would probably increase the concentration in serum. In regard to the latter, data from randomised, controlled, clinical trials have consistently shown that fish oil supplements improve endothelial function [9, 37-39], and two studies suggest that DHA may be the vasoactive component of fish oil [40, 41]. Recently, Leeson et al. [41] measured FMD and circulating fatty acid concentrations in 326 healthy young adults. They found a positive association between plasma levels of DHA and FMD scores and, consistent with findings reported here, this effect was evident in subjects with elevated triacylglycerols, but not in a control group with normal triacylglycerols. Khan et al. [37] found that fish oil increased the DHA content of erythrocyte phospholipids, and that subjects with the highest DHA concentrations after treatment had better endothelial function than subjects with low DHA concentrations. Our results should be confirmed after chronic treatment with n-3 fatty acids, and plasma concentrations of the bioactive fatty acids should be included in future studies.

In contrast to previous reports of FMD impairment following consumption of olive oil [14], we showed that FMD was not reduced following a meal containing $50 \mathrm{~g}$ of fat, including $\sim 30 \mathrm{~g}$ of oleic acid from high-oleic safflower oil. Our results confirm the findings of Williams et al. [15], who administered $64 \mathrm{~g}$ of olive oil or safflower oil, 
and found that neither source of unsaturated fatty acids had any acute effect on FMD, even after the oils were oxidised by heat. Given the mixed, and somewhat contradictory information about the effects of olive oil $[14,15]$, oleic acid $[15,16]$, and a Mediterranean diet $[18,21]$ on endothelial function, more work in this area is clearly needed.

Our finding that n-3 fatty acids increased FMD acutely also appears to be at odds with a study by Vogel et al. [14], who showed that a high-fat meal containing $50 \mathrm{~g}$ of fat from salmon had no impact on FMD. However, the sample tested by Vogel et al. included only healthy young adults with very low fasting triacylglycerols levels, and FMD improvements in the present study were only seen in subjects with high triacylglycerols. In addition, it is possible that other nutrients present in the fish altered the acute vascular effects of the $\mathrm{n}-3$ fatty acids it contained.

We found no significant associations between postprandial changes in glucose, insulin, blood pressure, or heart rate, and change in FMD. However, because the peak insulin response occurred at $2 \mathrm{~h}$, and FMD was not assessed until $4 \mathrm{~h}$ postmeal, we could not assess whether transient increases in insulin after a high-fat meal would affect vascular function. In addition, our enrolment criteria were designed to recruit a homogeneous sample of individuals with established diabetes but no clinically evident cardiovascular disease, and this may have excluded subjects with the largest postprandial changes in triacylglycerols, glucose and insulin. However, $\mathrm{HbA}_{1} \mathrm{c}$ levels in this sample ranged from $5.4 \%$ to $8.9 \%$ indicating that glucose control was not optimal despite the fact that the majority were taking one or more hypoglycaemic agents. These results cannot address whether patients with more advanced diabetes and/or cardiovascular disease would show a similar response to omega-3 fatty acids. Ros et al. [42] recently reported that FMD was significantly increased in healthy adults with hypercholesterolaemia after a mixed meal containing omega-3 fatty acids, suggesting that nondiabetic subjects may also benefit from including omega-3 fatty acids in their habitual diets.

Another study [43] proposed that the apparent reduction in FMD after a meal high in saturated fat is actually the result of peripheral vasodilation (measured as an increase in basal artery diameter), rather than a change in endothelial function in itself, and this pattern was confirmed in some [44-46] but not all [23, 33, 47] recent studies. In the present study, neither baseline artery diameter nor peak artery diameter were significantly changed after high-fat meals that are rich in unsaturated fatty acids. The meals had no significant impact on the magnitude of hyperaemic flow following cuff release, and adjustment for group differences in age and metformin status did not alter the pattern of vascular or triacylglycerols responses to the meals.

Assessment of FMD is not currently recommended as a clinical marker of cardiovascular disease risk, in part because small variations in technique have large effects on FMD estimates [11]. We propose that triacylglycerols status be used to identify patients who may benefit from n-3 fatty acids, and our data suggest that marine and plantderived n-3 fatty acids would be equally effective. Recent studies have found lasting improvements in FMD after longer term treatment with fish oil [9, 37-39], and with plant-derived ALA [42]. For example, Ros et al. [42] showed that a fivefold increase in dietary ALA from walnuts increased FMD by $33 \%$, even in the context of a Mediterranean-style background diet.

It is also important to consider the meaning of these effects in the context of recommended dietary intakes of n-3 fatty acids. Americans typically consume $\sim 1.6 \mathrm{~g} / \mathrm{d}$ of n-3 fatty acids from plant and marine sources combined [48] and vegetable oils are the primary source. In this study, we provided $3.5 \mathrm{~g}$ of ALA and $4.8 \mathrm{~g}$ of EPA+DHA as part of a $50 \mathrm{~g}$ fat load. The National Academies [49] recommend that a nutritionally adequate intake of ALA is $0.8-1.1 \mathrm{~g} /$ day, and $10 \%$ of this amount may be supplied as EPA and DHA. The American Heart Association (AHA) Dietary Guidelines 2000 recommend consumption of at least two servings of fish (preferably oily) per week to decrease risk of cardiovascular disease [50], and this would typically provide approximately $350-450 \mathrm{mg}$ of EPA and DHA per day (one serving of fatty fish, i.e., 85 $113 \mathrm{~g}$, provides approximately 1.2 to $1.6 \mathrm{~g}$ of EPA and DHA). The AHA Science Advisory "Fish consumption, fish oil, n-3 fatty acids, and cardiovascular disease" [51] recommends that patients with documented CHD consume approximately $1 \mathrm{~g}$ of EPA+DHA per day, preferably from oily fish. In addition, EPA+DHA supplements could be considered in consultation with the physician. The AHA acknowledges that for ALA, total intakes of approximately 1.5 to $3 \mathrm{~g} /$ day seem to be beneficial for cardiovascular disease risk reduction [51]. This study could not address the effects of more moderate doses of omega-3 fatty acids. However, Ros et al. found improvements in FMD with plant-based omega-3 fatty acids within a meal that contained less fat $(19-27 \mathrm{~g})$ than the meals tested in the present study.

In summary, the present study showed that a meal containing $50 \mathrm{~g}$ of fat, primarily from unsaturated fatty acids, was not associated with impaired endothelial function. In patients with type 2 diabetes and high fasting triacylglycerols levels, meals containing 3 to $5 \mathrm{~g}$ of either plant or marine-derived $n-3$ fatty acids actually significantly improved postprandial lipaemia and endothelial function. Our data support the view that the vascular effects of a meal are dependent on both the fatty acid composition of the meal, and the metabolic status of the subject. From a clinical perspective, our results suggest that adjunctive treatment with n-3 fatty acids could enhance endothelial function even in patients who are already taking hypoglycaemic drugs. Future studies should assess whether the apparent vascular benefits of n-3 fatty acids are observed after long-term administration, and test whether changes in markers of oxidative stress, serum fatty acids, and L-arginine and nitric oxide metabolism are potential mechanisms for these effects. 
Acknowledgements Funding was provided by Ross Products Division, Abbott Laboratories, Columbus, Ohio, USA. Additional funding was provided by an Albert and Lorraine Kligman Graduate Fellowship awarded to K. D. Hecker, and from the General Clinical Research Center of The Pennsylvania State University (NIH \#M01RR10732). We appreciate technical assistance provided by Matella Drum, Wake Forest University School of Medicine and Don Van Creveld of Acuson (Siemens Ultrasound Division), and Katrina LaRue Hurston at Penn State. Kari D. Hecker is now at Frito-Lay, Plano, TX, USA, and Stephanie L. Schoemer is in the Department of Human Nutrition, Michigan State University, Lansing, Michigan, USA. This study was funded by the Ross Product Division of Abbott Laboratories. The authors have stated that the results were not influenced by Abbott Laboratories.

\section{References}

1. Schachinger V, Britten MB, Zeiher AM (2000) Prognostic impact of coronary vasodilator dysfunction on adverse longterm outcome of coronary heart disease. Circulation 101:18991906

2. Makimattila S, Yki-Jarvinen H (2002) Endothelial dysfunction in human diabetes. Curr Diabetes Rep 2:26-36

3. Makimattila S, Liu ML, Vakkilainen J et al (1999) Impaired endothelium-dependent vasodilation in type 2 diabetes. Relation to LDL size, oxidized LDL, and antioxidants. Diabetes Care 22:973-981

4. Vogel RA, Corretti MC, Gellman J (1998) Cholesterol, cholesterol lowering, and endothelial function. Prog Cardiovasc Dis $41: 117-136$

5. Sondergaard E, Moller JE, Egstrup K (2003) Effect of dietary intervention and lipid-lowering treatment on brachial vasoreactivity in patients with ischemic heart disease and hypercholesterolemia. Am Heart J 145:E19

6. Wang TD, Chen WJ, Lin JW, Cheng CC, Chen MF, Lee YT (2003) Efficacy of fenofibrate and simvastatin on endothelial function and inflammatory markers in patients with combined hyperlipidemia: relations with baseline lipid profiles. Atherosclerosis 170:315-323

7. Van Venrooij FV, van de Ree MA, Bots ML, Stolk RP, Huisman MV, Banga JD (2002) Aggressive lipid lowering does not improve endothelial function in type 2 diabetes: the Diabetes Atorvastatin Lipid Intervention (DALI) Study: a randomized, double-blind, placebo-controlled trial. Diabetes Care 25:1211-1216

8. Hu FB, Cho E, Rexrode KM, Albert CM, Manson JE (2003) Fish and long-chain omega-3 fatty acid intake and risk of coronary heart disease and total mortality in diabetic women. Circulation 107:1852-1857

9. McVeigh GE, Brennan GM, Johnston GD et al (1993) Dietary fish oil augments nitric oxide production or release in patients with type 2 (non-insulin-dependent) diabetes mellitus. Diabetologia $36: 33-38$

10. West SG (2001) Effect of diet on vascular reactivity: an emerging marker for vascular risk. Curr Atheroscler Rep $3: 446-455$

11. Hinderliter AL, Caughey M (2003) Assessing endothelial function as a risk factor for cardiovascular disease. Curr Atheroscler Rep 5:506-513

12. Plotnick GD, Corretti MC, Vogel RA (1997) Effect of antioxidant vitamins on the transient impairment of endotheliumdependent brachial artery vasoactivity following a single highfat meal. JAMA 278:1682-1686

13. Plotnick GD, Corretti MC, Vogel RA, Hesslink R Jr, Wise JA (2003) Effect of supplemental phytonutrients on impairment of the flow-mediated brachial artery vasoactivity after a single high-fat meal. J Am Coll Cardiol 41:1744-1749

14. Vogel RA, Corretti MC, Plotnick GD (2000) The postprandial effect of components of the Mediterranean diet on endothelial function. J Am Coll Cardiol 36:1455-1460
15. Williams MJA, Sutherland WHF, McCormick MP, Yeoman D, de Jong SA, Walker RJ (2001) Normal endothelial function after meals rich in olive or safflower oil previously used for deep frying. Nutr Metab Cardiovasc Dis 11:147-152

16. Ong PJ, Dean TS, Hayward CS, Della Monica PL, Sanders TA, Collins P (1999) Effect of fat and carbohydrate consumption on endothelial function. Lancet 354:2134

17. Franz MJ, Bantle JP, Beebe CA et al (2004) Nutrition principles and recommendations in diabetes. Diabetes Care 27(Suppl 1): S36-S46

18. Fuentes F, Lopez-Miranda J, Sanchez E et al (2001) Mediterranean and low-fat diets improve endothelial function in hypercholesterolemic men. Ann Intern Med 134:1115-1119

19. Massaro M, Carluccio M, DeCaterina R (1999) Direct vascular antiatherogenic effects of oleic acid: a clue to the cardioprotective effects of the Mediterranean diet. Cardiologia 44:507513

20. Ryan M, McInerney D, Owens D, Collins P, Johnson A, Tomkin GH (2000) Diabetes and the Mediterranean diet: a beneficial effect of oleic acid on insulin sensitivity, adipocyte glucose transport and endothelium-dependent vasoreactivity. Q J Med 93:85-91

21. Ambring A, Friberg P, Axelsen M et al (2003) Effects of Mediterranean inspired diet on blood lipids, vascular function and oxidative stress in healthy subjects. Clin Sci (Lond) 106:519-525

22. Williams MJ, Sutherland WH, McCormick MP, de Jong SA, Walker RJ, Wilkins GT (1999) Impaired endothelial function following a meal rich in used cooking fat. J Am Coll Cardiol 33:1050-1055

23. Evans M, Anderson RA, Graham J et al (2000) Ciprofibrate therapy improves endothelial function and reduces postprandial lipemia and oxidative stress in type 2 diabetes mellitus. Circulation 101:1773-1779

24. Ceriello A, Taboga C, Tonutti L et al (2002) Evidence for an independent and cumulative effect of postprandial hypertriglyceridemia and hyperglycemia on endothelial dysfunction and oxidative stress generation: effects of short- and long-term simvastatin treatment. Circulation 106:1211-1218

25. Vogel RA, Corretti MC, Plotnick GD (1997) Effect of a single high-fat meal on endothelial function in healthy subjects. Am J Cardiol 79:350-354

26. Coretti MC, Anderson TJ, Benjamin EJ et al (2002) Guidelines for the ultrasound assessment of endothelial-dependent flowmediated vasodilation of the brachial artery: a report of the International Brachial Artery Reactivity Task Force. J Am Cardiol 39:257-265

27. West SG, Wagner P, Schoemer SL et al (2004) Biological correlates of day-to-day variation in flow-mediated dilation in individuals with Type 2 diabetes: a study of test-retest reliability. Diabetologia 47:1625-1631

28. Sakata S, Imai T, Kamikubo K et al (1983) A solid phase radioimmunoassay for the detection of anti-insulin antibodies. Endocrinol Jpn 30(1): 23-28

29. Katz A, Nambi SS, Mather K et al (2000) Quantitative insulin sensitivity check index: a simple, accurate method for assessing insulin sensitivity in humans. J Clin Endocrinol Metab $85: 2402-2410$

30. National Cholesterol Education Program (2001) Third report of the expert panel on detection, evaluation, and treatment of high blood cholesterol in adults (Adult Treatment Panel III). In: National Cholesterol Education Program. National Institutes of Health, National Heart, Lung, and Blood Institute, Bethesda

31. Herrington DM, Fan L, Drum M et al (2001) Brachial flowmediated vasodilator responses in population-based research: methods, reproducibility and effects of age, gender and baseline diameter. J Cardiovasc Risk 8:319-328

32. Vogel RA (1997) Coronary risk factors, endothelial function, and atherosclerosis: a review. Clin Cardiol 20:426-432

33. Gaenzer H, Sturm W, Neumayr G et al (2001) Pronounced postprandial lipemia impairs endothelium-dependent dilation of the brachial artery in men. Cardiovasc Res 52:509-516 
34. Anderson RA, Evans ML, Ellis GR et al (2001) The relationships between post-prandial lipaemia, endothelial function and oxidative stress in healthy individuals and patients with type 2 diabetes. Atherosclerosis 154:475-483

35. Weintraub MS, Zechner R, Brown A, Eisenberg S, Breslow JL (1988) Dietary polyunsaturated fats of the W-6 and W-3 series reduce postprandial lipoprotein levels. Chronic and acute effects of fat saturation on postprandial lipoprotein metabolism. J Clin Invest 82:1884-1893

36. Williams CM (1997) Postprandial lipid metabolism: effects of dietary fatty acids. Proc Nutr Soc 56:679-692

37. Khan F, Elherik K, Bolton-Smith C et al (2003) The effects of dietary fatty acid supplementation on endothelial function and vascular tone in healthy subjects. Cardiovasc Res 59:955-962

38. Goodfellow J, Bellamy M, Ramsey M, Jones C, Lewis M (2000) Dietary supplements with marine omega-3 fatty acids improve systemic large artery endothelial function in subjects with hypercholesterolemia. J Am Coll Cardiol 35:265-270

39. Goode GK, Garcia S, Heagerty AM (1997) Dietary supplementation with marine fish oil improves in vitro small artery endothelial function in hypercholesterolemic patients: a doubleblind placebo-controlled study. Circulation 96:2802-2807

40. Mori TA, Watts GF, Burke V, Hilme E, Puddey IB, Beilin LJ (2000) Differential effects of eicosapentaenoic acid and docosahexaenoic acid on vascular reactivity of the forearm microcirculation in hyperlipidemic, overweight men. Circulation 102:1264-1269

41. Leeson CP, Mann A, Kattenhorn M, Deanfield JE, Lucas A, Muller DP (2002) Relationship between circulating n-3 fatty acid concentrations and endothelial function in early adulthood. Eur Heart J 23:216-222

42. Ros E, Nunez I, Perez-Heras A et al (2004) A walnut diet improves endothelial function in hypercholesterolemic subjects: a randomized crossover trial. Circulation 109:1609-1614
43. Raitakari OT, Lai N, Griffiths K, McCredie R, Sullivan D, Celermajer DS (2000) Enhanced peripheral vasodilation in humans after a fatty meal. J Am Coll Cardiol 36:417-422

44. Bae JH, Schwemmer M, Lee IK et al (2003) Postprandial hypertriglyceridemia-induced endothelial dysfunction in healthy subjects is independent of lipid oxidation. Int J Cardiol 87:259-267

45. Gokce N, Vita JA, Bader DS et al (2002) Effect of exercise on upper and lower extremity endothelial function in patients with coronary artery disease. Am J Cardiol 90:124-127

46. Fard A, Tuck CH, Donis JA et al (2000) Acute elevations of plasma asymmetric dimethylarginine and impaired endothelial function in response to a high-fat meal in patients with type 2 diabetes. Arterioscler Thromb Vasc Biol 20:2039-2044

47. Marchesi S, Lupattelli G, Schillaci G et al (2000) Impaired flow-mediated vasoactivity during post-prandial phase in young healthy men. Atherosclerosis 153:397-402

48. Kris-Etherton PM, Taylor DS, Yu-Poth S et al (2000) Polyunsaturated fatty acids in the food chain in the United States. Am J Clin Nutr 71:179S-188S

49. Institute of Medicine of the National Academies (2002) Dietary reference intakes for energy, carbohydrate, fiber, fat, fatty acids, cholesterol, protein, and amino acids. In: Dietary Reference Intakes. The National Academies Press, Washington, DC

50. Krauss RM, Eckel RH, Howard B et al (2000) AHA Dietary Guidelines: revision 2000: a statement for healthcare professionals from the Nutrition Committee of the American Heart Association. Stroke 31:2751-2766

51. Kris-Etherton PM, Harris WS, Appel LJ, for the Nutrition Committee (2002) AHA Scientific Statement: fish consumption, fish oil, omega-3 fatty acids, and cardiovascular diseases. Circulation 106:2747-2757 